\title{
Non-economic Factors in Development
}

\author{
NAJAMUL SAQIB KHAN
}

\section{INTRODUCTION}

Economic development in knowledgeable circles has a missing dimensionthe non-economic, which is not quantifiable. Development, a leading sector in national transformation, is rooted in nonmaterial factors and requires a positive feedback between culture, economy, and polity. I would invite attention to an insightful comment from a practising professional economist: 'The need for economic growth in a developing country has few if any economic springs. It arises from a desire to assume full status by taking part in an industrial Civilisation, participation in which alone enables a nation or individual to compel others to treat it as an equal. Inability to take part in it makes a nation militarily powerless against neighbours, administratively unable to control its own citizens, and culturally incapable of speaking the international language'.

The functioning of a developmental state has to be viewed in the context of regional and international geopolitical environments. First, in the case of Pakistan, the troubled relationship with India, a big country assailed by the anxieties and complexes of a small and beleaguered nation aspiring to a super-power status with hegemonic goals, has cast a lengthening shadow across its path of development. Second, our achievement of political independence coincided with the onset and intensity of the cold war. In the post-independence period, the stream of national freedom merged with the tidal waves of the cold war and became visibly polluted. A bipolar world, where the contending superpowers were vying with each other to win the allegiance and support of the fledgling states, virtually sucked the latter into the geopolitical game as it was being played on the global stage and deflected their attention from tackling developmental issues on the home front with a sense of urgency. Preoccupation with external dangers narrows the window of opportunity for an economic breakthrough in developing countries. Third, the cold war provided us with opportunities to tap external sources for balance of payments and project aid and to secure supply of arms on concessional basis. In fact, our prolonged and largescale dependence on assistance from highly industrialised countries hardened into an addiction to it. Instead of progressively phasing out aid, it became virtually a

Najamul Saqib Khan is a former Ambassador of Pakistan. 
permanent prop of the status quo. Finally, the Soviet invasion of Afghanistan and its aftermath has saddled us with serious problems of inflow of arms, drugs, refugees, and torn asunder the social fabric of a soft state. In the post-cold war era, where geoeconomics seems to be replacing geopolitics as a determinant in international relations, we have to make a creative adjustment to the emerging realities, and renew our commitment to development in an era of diminishing availability of external resources.

\section{CULTURE AND DEVELOPMENT}

An unexamined life is not worth living. We have to examine the role of culture in development. Culture, for our purposes, is to be defined as the values, attitudes and beliefs that shape behaviour and institutions. 'Of course, culture matters. People are ruled by passions, ideologies and their values and even when economic interests prevail, they need to be justified by values. The differences between nations, especially in the levels of development, are due to education and culture'. A developmental state as against a development resistant state has to change traditional mental models and create a climate congenial (a) to dissemination of knowledge and skills among the young through education; (b) to selection of people for jobs on the basis of competence and merit; (c) to providing opportunities to individual or collective enterprise and fostering competition; and (d) to endorsing entitlement of people to the fruits of their labour and deferred gratification.

'Culture is the mother of institutions'. Napoleon hit the nail on the head when he remarked 'Men are powerless to secure the future, institutions alone fix the destinies of nations'. According to Landes (1988), the political and social institutions geared to achieving self-sustaining growth 'would:

- Secure rights of property.

- Secure rights of personal liberty.

- Enforce rights of contract.

- Provide a government of laws rather than men.

- Provide responsive government, one that will hear complaint and make redress.

- Provide honest government, there should be no rents to favour and position.'

Sen (1999) comments: 'Individuals live and operate in a world of institutions. Our opportunities and prospects depend crucially on what institutions exist and how they function'. Fukuyama (1995) has disseminated the view that social capital is as important as physical capital and a sine qua non of rational economic behaviour. Social capital is defined by him 'as... set of informal values and norms shared among members of a group that permits them to cooperate with one another. If the members of the group come to expect that others will behave 
reliably and honestly, they will come to trust one another. Trust acts like a lubricant that makes any group or organisation run more efficiently.... has a large and measurable economic value.'

Power in a society is indissolubly linked with culture. It is the cultural dimension that creates the values, norms, symbols and practices for the exercise of power. The longing of the public for charismatic leadership in our region is fed by myths and historical memories that legitimise the concentration of power in a single individual. Charismatic leadership retards the growth of institutions required for modernisation and has recourse to symbolic solutions of problems. Charisma is to be equated with heroic leadership that rejects economic realities perceived as prosaic. Economic reality and myths of effortless quantum leaps occupy very different areas of human consciousness.

\section{IDENTITY VERSUS CHANGE}

One of the dilemmas of development is posed by the conflicting pulls of identity and development. The compelling question in some influential circles is who are we and rarely 'what are we going to do and how can we can do it'. An insightful scholar, surveying the landscape of the Middle East, has analysed this obsession with clarity. In times of weakness at home and challenge from abroad in a developing country, the issues of identity and authenticity occupy the foreground. The feelings of insecurity and vulnerability lead to the pervasive importance of the self, of the 'roots and heritage', and the receding into background of existential and developmental issues. What is more, the 'search for identity is only manifested at a static level of reaction and emotion... is a purely theoretical issue concerned mainly with displaying ourselves to others in endless, repetitive letters of introduction'. The Germans and the Japanese were deeply concerned with issues of authenticity and identity; but in their cases identity was viewed in dynamic relationship to national advancement requiring reinterpretation and remodelling. Economic development is forward looking in its perspectives and aims at building a better future for the people through their efforts by creating the incentive of making short-term sacrifices for long-term good and by steering them towards adaptive and accommodative inclinations in a changing world. We should continue to pay homage to our forefathers without defaulting on our obligations to our children and grandchildren. In developmental planning, the dilemma between the pull of the past and the push of the future is to be resolved by keeping in the forefront the intergenerational dimension requiring sacrifices by the present generation for the succeeding ones. Such trade offs are of the essence in economic progress.

\section{A HARD OR FIERCE STATE VERSUS A STRONG STATE}

There is a difference between a hard or a fierce state and a strong state: A fierce state is not a strong state it mainly relies on coercive and administrative 
instruments in penetrating society. The strong state, on the other hand, relying on flexibility and persuasiveness, demonstrates capacity to carry out developmental tasks through collaboration with centres of power in society rather than exercising dominion over them. A distinction between 'despotic' power and 'infrastructural' power goes to the heart of the matter. 'The fierce state excels in despotic power, the strong in infrastructural power.' The despotic power of a state, released from legal restraints, enables it to act in an arbitrary manner and conveys an impression of omnipotence. This impression is dispelled before long when cracks are visible in translating its commands into reality. It uses symbolism and imagery as aids to ruling but seldom seeks legitimacy through performance and good governance. The infrastructural power is reflected in the capacity 'to penetrate society and to organise social relations.' The capacity of a state to collect revenue through direct rather than indirect taxation is a reliable indicator of intrinsic strength and acceptance by the public of its legitimacy on the basis of performance. To sum up, the pretensions of despotism in accelerating development are not to be taken at its face value.

\section{AUTHORITY VERSUS POWER}

The decision-makers and power wielders in developmental states carry a mental map that fails to make a distinction between authority and power, a distinction that eludes the grasp of the best and brightest in South Asia. Authority means the possession of unwritten power and the gravitational influence of exemplary conduct on receiving respect and compliance. 'With authority inevitably comes influence but not necessarily power in the sense of capacity to coerce others to do what they would not otherwise do'. The differentiation between authority and power is of profound significance because it recognises a fundamental reality that a state does not have such an inexhaustible reservoir of coercive power as can be continually drawn upon for enforcing commands. Coercive power is to be held in reserve and used sparingly on infrequent occasions. A state's main reliance should be on authority to generate consensus on policies through negotiation and on participation with a view to clearing the decks for take-off into sustained growth. Leadership needs authority derived from performance on the unassailable ground that it entails economy in deploying resources to secure voluntary compliance with the programmes of a developmental state.

\section{CRISIS OF IMPLEMENTATION}

Related to the issues discussed so far is the crisis of implementation, the Achilles' heel of governments in developing countries. It invites the comment: 'Plus ca change plus c'est la meme chose,' Laws, regulations Z, executive decrees and legislative enactments encounter resistance, delays, cost overruns, and even derailment at the stage of implementation. The carrying out of decisions embodying high purpose and lofty goals often takes place in a routinised, listless, anaemic 
manner, sometimes with the intention of negating their effects. The non-delivery of public goods to designated beneficiaries and their appropriation by privileged intermediaries casts a cloud on the commitment of leadership to meet the basic human needs of the people. The delivery mechanism is riddled with holes. Crisis of implementation in Pakistan is manifested in the fact that we have non-disbursed and unutilised committed aid of the magnitude of around ten billion dollars.

\section{RHETORIC OF REACTION}

Innovative ideas and policies concerning economic development and social change invariably encounter reactionary waves swept up by conservative thought. Hirschman (1991), author of the Rhetoric of Reaction, has focused on 'the major polemical postures and monoeuvres likely to be engaged by those who set out to debunk and overturn progressive policies and movements of ideas'. He comes up with three principle reactive-reactionary theses. According to the perversity thesis, 'any purposive action only serves to exacerbate the conditions to be remedied. The futility thesis holds that attempts at social transformation will be unavailing, that they will simply fail to make a dent'. Finally, the jeopardy thesis maintains that the price exacted by positive change or reform will be too high as it undermines some previous and cherished accomplishment.

It is the futility thesis that has been increasingly deployed by some segments of our èlites to weaken the drive for development. Obsession with futility of efforts and failure complex has been fostered by their incapacity and unwillingness to absorb the pain of changing the status quo, and by our ruling class 'style to make big things seem small, exciting things boring, new things familiar'. Given their intellectual capacities, economic well-being and predominant influence on the climate of opinion, they have to rise equal to the responsibility of a leadership role rather than remain 'apathetic, anomic and alienated. They are a highly privileged minority and noblesse oblige summons them to provide deliverance from the corrosive effects of failure complex. 'Such leadership occurs when one or more persons engage with others in such a way that leaders and followers raise one another to higher levels of motivation and morality'.

\section{THE ROLE OF ELITES}

The èlites in developing countries, comprising those who have access to education, power and wealth, are really part of the problem rather than part of the solution. To give a concrete expression, they consist of the politicians, the military, landowners, civil servants, businessmen and the intelligentsia. The role of èlites in late developing countries, impatient to catch up with the highly industrialised countries, is of pivotal importance in modernisation. The great majority of the people have to be awakened from their deep slumber and stirred into action to reconstruct their lives and their environment. The èlites have to exemplify new values in their 
conduct and performance; they have to set a high standard of achievement in high offices occupied by them; they have to provide an agenda setting forth goals and priorities; they have to take upon themselves rather than delegate the all important task of organising a functioning as well as a leak-free delivery system.

For èlites in countries that had experienced foreign subjugation, the challenge from the West was met by political and legal systems patterned after the Western model. They perceived the gap in relation to the West as essentially constitutional and political rather than educational and technological. It is hardly an exaggeration to state that the belief was widespread among them, that provided entry into the political kingdom was ensured, the gates to other kingdoms would be automatically opened to emerging nations. Given the East-West conflict in the cold war which lasted almost 50 years, their goals shifted from national self-reliance to foreign dependence, from mobilising domestic resources and shaping national consensus to negotiating loans and grants from abroad and from grass roots development to planning tailored to meet the specifications of aid givers.

Exploitative, parasitical, and sub-national in outlook, their involvement in fomenting ethnic and regional splits in our country is crystal-clear. Obsessed as they are with symbols rather than substance, they indulge in the perverse reasoning that access to nuclear weapons is an equaliser among nations and a ticket for admission to the league of Great Powers. When abroad, they are clamouring for equality among nations at international conferences, but back at home, they stifle egalitarian impulses and have minimal interest in eradicating poverty.

The èlites have demonstrated by their conduct that they lack fire in their bellies, and have become a constituency for the maintenance of the status quo. The ruling groups 'want highways for their cars, not lanes through muddy settlements; they want airports for flights abroad, not bus service to bring squatters to jobs. They demand water for houses with plumbing, not for those in shacks. Hospitals and schools must be built where the well-off live; clinics and classes in the slums can wait'. The growth of the middle class linked to the diversification and modernisation of economy with decent paying jobs in the market sector is to be fostered to clip the wings of èlites and build a strong coalition for change. The verdict of economic history has been that an expanding and flourishing middle class is the backbone of sustained growth and democracy.

\section{PRIMACY OF UNIVERSAL PRIMARY EDUCATION}

One of the questions that continues to haunt me is why in Pakistan we have neglected education in our developmental planning, Education, the signature of nation-building and the 'cheap defence of nations', has been put on the back burner. Education is a comprehensive topic comprising primary, secondary, college education. My focus in this essay is on the introduction of universal primary education. The young leaders of Japan in the 1870s after the Meiji Restoration fully 
realised the indispensable role of universal elementary education in achieving equality with the West. Why have the ruling circles, the politicians and planners in our land, given lip-service to it but relegated basic education to the bottom rung in mapping out priorities and allocating resources?

We have to attempt a searching analysis of our cosmetic commitment to the spread of education in our country. First, we are not an education-conscious society compared to the Confucian nations in East Asia. Second, we have to contend with the aftermath of the British rule in the subcontinent. 'The last remaining Englishmen are the Indians and Pakistanis'. The British society was èlitist in character; the Oxbridge legacy is continuing to cast an ominous shadow across their national landscape even in the new millennium. In England, university education was accorded top priority and access to equal opportunities for schooling in the formative years of childhood was denied. Public schooling, a euphemism for privileged learning for the offspring of the èlite, was a crucial factor in fostering classconsciousness and social resentment in the island nation. We loathed foreign rule but our èlites adopted the British educational model. 'Slaves by their own compulsion. In made game they break their manacles, and wear the name of freedom, graven on a heavier chain'. Second, feudalism with its boastful credo that the best fertiliser for a farmer is the sound of footsteps of a master landowner is the bane of diffusion of education. Landowning class is viscerally inimical to the greater awareness and consciousness of tillers of the soil through grass roots learning. Third, leaving aside the rural areas, feudal values have penetrated all segments of society including the urban èlite and the ruling circles. Fourth, we have short-term horizons and are reluctant to look upon education as the due from the present to future generation. Education is 'a lead time investment and quick results cannot be expected'. A penetrating comment on education as an investment in future merits quotation: 'If you plan for a year, plant a seed. If for ten years, plant a tree. If for a hundred years, teach the people. When you teach the people, you will reap a thousand harvests.' Fifth, the focus on ballot box, as the sole route to democracy, has been accompanied by a massive devaluation of public education, which is an indispensable condition for its successful functioning. We should keep on reminding ourselves that 'democracy without literacy is hypocrisy without limitation'.

We have to understand history in order to make history. We have no recorded example in history of a developed country with a large immobilised mass of illiterate citizenry. We have incontestable contemporary evidence of late developing countries lagging behind in the race for advancement without the liftup of a critical mass of educated citizens. The goal of public education lies not in the creation of a brilliant elite, but in the generation of a high average level of capability. A rising standard of living of a country depends upon an upward movement in productivity; the increase in productivity itself hinges on a rise in the average level of capability. 


\section{LAND REFORM}

Of the postwar reforms instituted in Japan-the sole Asian nation that has caught up with Western countries, the one which had the most far-reaching effects was the land reform. The land tenure changes resulted in a major redistribution of land affecting seven million farmers and in the transformation of rural society. The acid test of a land reform programme is the percentage of the total cultivable area released for distribution to the landless. 37.5 percent of the entire cultivable area in Japan was transferred to 4.7 million tenants. The owner farmers, who constituted about 30 percent of the farming families in 1945, had risen to 65 percent in 1950 . Tenanted area dropped from 46 percent to 10 percent of the agricultural land. Tenant farmers, who owned no land themselves, dropped from 28 percent to 5 percent of all farm households. Keeping in view the high level of rents in prewar Japan, rents which amounted to 16.6 percent of total agricultural income in 1934-36 dropped to about 0.2 percent in 1953 .

The size of land actually redistributed in India and Pakistan after independence has not made a significant dent on property relationships in the agricultural sector. The numbers of tenants who have become owners of land cultivated by them have not been large. Given this grim reality, the security of tenancy assumes the proportions of a crucial problem. The measures adopted in tenancy legislations in the subcontinent have proved ineffectual in safeguarding the rights of tenants: their ejectments continue under the guise of voluntary surrenders and informal sharecropping arrangements remain uncontested in substantial regions. Myrdal (1968) has commented, 'In the social environment of South Asia, impartiality in the administration of tenancy laws can hardly be expected, even in the absence of corruption'. Where it has been possible for the landlord to win the active support or acquiescence of the coercive apparatus of the state to lead with impunity a parasitic existence and to collect rents, there is clearly little motivation to comply with agricultural laws.

As pointed out by Prosterman and Riedinger (1987), authors of Land Reforms and Democratic Development: 'The acute form of land tenure problem on our planet is now highly concentrated. Of the 50-54 million agricultural labourer families in all of the non-industrialised countries, between 36.5 and 40 million, or 73-74 percent, are found in five Asian countries: India, Pakistan, Bangladesh, Indonesia and the Philippines. Of the estimated 33-46 million tenant families, between 28 and 40 million are in the same five countries'. According to them, of the 83-100 million landless agricultural families in the non-industrialised countries, approximately 7880 percent are concentrated in these five countries. They go on to prognosticate on the basis of their past experience that a substantial danger of major revolution exists for any country 30 percent or more of whose population consisted of landless peasants and a critical danger where the percentage rose to 40 percent. In the light of their current analysis, the authors would alter that somewhat predicting a substantial 
danger of major revolution for any country burdened with a total population consisting of 25 percent or more landless peasants. In the light of their definitive study of land reform, the five Asian countries including Pakistan, where 25 percent or more of the whole population comprises landless agriculturists, face a clear and present fact of upheaval if land tenure grievances are not resolved.

Not only does an inequitable land tenure system lead to large-scale landlessness which undermines political stability; it is a major impediment to the improvement of agricultural productivity, to the elimination of poverty and in fact to the entire development process. 'The peasant has to be transformed into a farmer producing for the market instead of his own consumption and that of the overlord'. Land reforms and its effective implementation is to be accorded high priority in a redesigned strategy for development in the clear knowledge that it will encounter protracted and stiff resistance from the beneficiaries of the status quo. Land reform may be looked upon by sceptics as the beating of a distant drum, but it echoes the heartbeats of the great majority of our population languishing in the rural areas and barely visible on the urban radar screen of our national life. History has yet to witness an economic take-off in a sustained manner in late industrialising countries without authentic land reforms and universal primary education.

\section{THE MYSTERY OF CAPITAL AND EMPOWERMENT OF PEOPLE}

In The Mystery of Capital, a pioneering book and an intellectual tour de force, its author De Soto (2000) sets out a blueprint targeted at overcoming poverty and bringing black markets into the mainstream of developing economies. Its subtitle is Why Capitalism Triumphs in the West and Fails Everywhere Else. I will attempt a condensed summary of his findings relevant to the themes of this essay. 'The hour of the greatest triumph of capitalism is its hour of crisis'. The fall of the Berlin Wall demonstrated that Capitalism alone provides a viable framework for developing and running a modern economy. Third world and former communist countries have carried out prescriptions of fiscal discipline, phasing out of subsidies, giving incentives to foreign investment and progressively reducing trade barriers. When the balance sheet is drawn at the beginning of the new millenium, the results flowing from the structural adjustment programmes of the International Monetary Fund and the World Bank have been disappointing: decline in real incomes, swelling of the numbers of people living below the poverty line, growing economic anxiety and social resentment. In developing countries, capitalism is regarded as creating islands of prosperity for a privileged minority surrounded by a sea of human misery. Westerners blame third world peoples for their deficits in entrepreneurial spirit and market orientation. De Soto challenges this critique by saying that the cities of the third world and the former communist countries are teeming with entrepreneurs and that their inhabitants, even the poorest, save and acquire assets. In Egypt alone, the assets of the poor are 55 times greater than all the recorded foreign investment 
including the financing of the Suez Canal and the Aswan Dam. By his calculations, the total value of the real estate held but not legally owned by the poor of the third world and former communists nations is at least 9.3 trillion U.S. dollars.

The grim reality, according to De Soto, is that the considerable assets of the poor remain 'dead capital' and at least 80 percent of the population in these countries cannot establish legal title to the assets and live outside the legal system. They cannot inject life into their assets and make them generate capital because the existing laws keep them out of the legal property system. In Egypt, a person wanting to acquire and legally register a plot on a state owned desert has to make his way through at least 77 bureaucratic procedures at 31 public and private agencies. Compliance with procedures will take from 5 to 14 years. To put up a legal dwelling on former agricultural land would take six to eleven years of bureaucratic wrangling. In Haiti, the poorest nation in Latin America, it takes nineteen years of slow walk through the procedural thicket to acquire lawful land. The author, Bubbling with Innovative Ideas, says again and again that the challenge is to convert dead assets into legal titles. The legal title is required as collateral for borrowing for investment. It is a widespread but mistaken view that capital is created by money. The reality is that capital is created by people whose 'property systems helped them to cooperate and think how they can get the assets they accumulate to deploy additional production'. The substantial increase of capital in the West over the past two centuries is rooted in reformed and integrated property systems, which opened new opportunities for budding entrepreneurs, cut off from the mainstream, to realise the potential of their assets and to utilise them 'to generate the non-inflationary money with which to finance additional production and wealth for the nation'.

De Soto has persuasively highlighted his belief that the prevailing state of affairs in the third world which denies opportunities to the majority of mankind is remediable provided the governments have the will to accept the following:

- All people save in one form or another and the assets of the poor need to be better documented.

- What is missing are the legally integrated property systems designed to convert their labour and saving into capital.

- Civil disobedience and mafias of today are the outcome of exodus from rural to urban areas where they face impenetrable barriers denying them entry into legally sanctioned economic activities.

- Designing and implementing a property system that creates capital is a major political challenge involving grass roots contact with people, recognition that social contracts underpin enforceable laws and overhauling the legal system.

- Empowering the people as the foundation of a thriving economy and society.

- Hernando agenda and vocabulary have been slightly amended by me. 


\section{CONCLUSION}

In conclusion, the traditional economists have been sceptical about the vital links between cultural values and human progress. Federal Reserve Board Chairman, Alan Greenspan, belonged to the traditional school until the dismal economic failure in Russia in the 1990s after the collapse of the Soviet Union. His strong belief was that human beings are endowed by nature with capitalistic habits and that their release from communism would automatically establish a free market entrepreneurial system. The debacle in Russia called for revisiting the assumption that capitalism was human nature and Greenspan reached the conclusion 'that it was not a nature at all but culture.' Culture and its inseparable twin education highlight the importance of microeconomics as the foundation of national prosperity. Macroeconomics underlines the need of a legal and predictable framework for economic growth; but the rise in productivity takes place at the microeconomic level of an individual enterprise with its competitive spirit, dynamism and risk taking.

We cannot violate with impunity the time tested laws of economic progress and close our eyes to the unambiguous lessons from the fate of stagnant and nonperforming societies and harbour the illusion that a special immunity from the consequences of our entrenched resistance to change has been bestowed on us. We should shed the psychology of victimhood, abandon the search for simple panaceas, and heed the clarion call to change prevailing attitudes and to build human, social and institutional capital at a fast pace.

\section{REFERENCES}

De Soto, Hernando (2000) The Mystery of Capital. New York: Basic Books.

Fukuyama, Francis (1995) Trust: The Social Virtues and the Creation of Prosperity. New York: The Free Press.

Harrison, Lawrence E., and Samuel Huntington (2000) Culture Matters. New York: Basic Books.

Hirschman, Albert (1991) The Rhetoric of Reaction: Perversity, Futility, Jeopardy. Cambridge, Mass: Harvard University Press.

Landes, David S. (1998) The Wealth and Poverty of Nations: Why Some are so Rich and Some are so Poor. New York: W. W. Norton and Company.

Myrdal, Gunnar (1968) Asian Drama: An Inquiry into the Poverty of Nations. Volume II, Pantheon. New York: Twentieth Century Fund.

Prosterman, Roy L., and Jeffrey M. Riedinger (1987) Land Reform and Democratic Development. Baltimore: The John Hopkins University Press.

Sen, Amartya (1999) Development as Freedom. Oxford: Oxford University Press.

The comments on the paper were not received in time for press. Ed. 